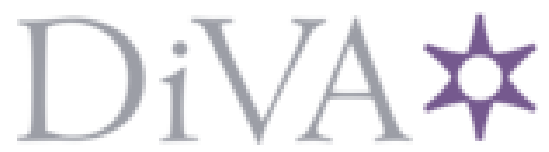

http://www.diva-portal.org

\title{
Postprint
}

This is the accepted version of a paper published in Alimentary Pharmacology and Therapeutics. This paper has been peer-reviewed but does not include the final publisher proof-corrections or journal pagination.

Citation for the original published paper (version of record):

Zhulina, Y., Cao, Y., Amcoff, K., Carlson, M., Tysk, C. et al. (2016)

The prognostic significance of faecal calprotectin in patients with inactive inflammatory bowel disease.

Alimentary Pharmacology and Therapeutics, 44(5): 495-504

http://dx.doi.org/10.1111/apt.13731

Access to the published version may require subscription.

N.B. When citing this work, cite the original published paper.

Permanent link to this version:

http://urn.kb.se/resolve?urn=urn:nbn:se:oru:diva-51532 


\section{Prognostic significance of faecal calprotectin in patients with inactive inflammatory bowel disease}

\section{Authors:}

Yaroslava Zhulina, ${ }^{1}$ Yang Cao, ${ }^{2,3}$ Karin Amcoff, ${ }^{1,4}$ Marie Carlson, ${ }^{4}$ Curt Tysk, ${ }^{1}$ Jonas

Halfvarson $^{1}$

\section{Affiliations:}

${ }^{1}$ Department of Gastroenterology, Faculty of Medicine and Health, Örebro University, SE 701

82, Örebro, Sweden

${ }^{2}$ Clinical Epidemiology and Biostatistics, School of Medical Sciences, Örebro University, SE

701 82, Örebro, Sweden

${ }^{3}$ Unit of Biostatistics, Institute of Environmental Medicine, Karolinska Institutet, SE 17177 ,

Stockholm, Sweden

${ }^{4}$ Department of Medical Sciences, Gastroenterology Research Group, Uppsala University, SE 75185 Uppsala, Sweden

Short title: Prognostic significance of faecal calprotectin

\section{Corresponding author:}

Yaroslava Zhulina, MD Department of Gastroenterology,

Faculty of Medicine and Health, Örebro University, SE-70182 Örebro, Sweden

Phone $+46(0) 58666737$

Fax +46(0)196021774

E-mail: yaroslava.zhulina@ regionorebrolan.se 


\section{Abstract}

Background: Faecal calprotectin, an established biomarker used to assess mucosal inflammation, has been shown to correlate with endoscopic activity in inflammatory bowel disease (IBD). Longitudinal monitoring of faecal calprotectin, however, has rarely been employed beyond assessment of therapy response and post hoc analyses of clinical trials.

Aim: We studied whether consecutive measurements of faecal calprotectin every third month are useful for monitoring patients with IBD in clinical remission.

Methods: Patients aged 18 years or older, with a known diagnosis of IBD in clinical remission, were prospectively studied. Patients provided faecal samples every third month and were prospectively followed until the first clinical relapse or the end of the two-year follow-up period. Measurements (EK-CAL, Bühlmann Lab. AG, Switzerland) were done at the end of the study. A Cox model with time-dependent covariates was used for analysis.

Results: Among 104 patients, Crohn's disease $(n=49)$ and ulcerative colitis $(n=55), 37$ had a relapse. A doubling of faecal calprotectin level between two consecutively collected samples was associated with a $101 \%$ increased risk of relapse (HR: $2.01 ; 95 \% \mathrm{CI}: 1.53-2.65 ; \mathrm{p}<0.001)$. The relative risk of relapse attenuated with time (HR: 0.80; 95\% CI: $0.75-0.86 ; \mathrm{p}<0.001)$, by a $20 \%$ decrease in risk of relapse per three-month period since the sample was obtained.

Conclusions: By consecutively measuring faecal calprotectin every third month, we quantified the risk of relapse related to faecal calprotectin change and observed attenuation of the risk across time. Our data suggest that longitudinal monitoring of faecal calprotectin is informative in predicting relapse in IBD.

Keywords: Inflammatory bowel disease, longitudinal monitoring, faecal calprotectin, timedependent covariates 


\section{Introduction and Aim}

Inflammatory bowel disease (IBD) including the two major forms, Crohn's disease and ulcerative colitis, is an inflammatory condition of the gastrointestinal tract characterized by periods of remission and intermittent relapses. The disease entity is associated with decreased quality of life, especially during relapses when treatment must be intensified. Currently, there are limited possibilities to predict the future disease course for an individual patient. Mucosal healing is presently the best prognostic marker, ${ }^{1}$ being associated with reduced risk of clinical flares within the following two-year period. ${ }^{2}$ IBD, however, is a life-long disease. Repeated colonoscopies are generally not accepted by patients and are associated with procedure-related risk and substantial cost.

Inflammatory markers in blood, such as C-reactive protein (CRP) and erythrocyte sedimentation rate, are useful to confirm ongoing mucosal inflammation but of less value to predict a future relapse, since elevated levels of these markers have not been found to precede a clinical flare. . $^{3,4}$ Faecal-based biomarkers, such as faecal calprotectin, might represent a better prognostic tool. ${ }^{5,6}$ Calprotectin accounts for approximately $40 \%$ of the cytosolic content of neutrophils and is released upon neutrophil activation. A correlation between the concentration of faecal calprotectin and endoscopic activity has consistently been reported in both ulcerative colitis and Crohn's disease. ${ }^{7-12}$ Increased faecal calprotectin, measured at a single occasion, has also been associated with an increased risk of a future flare, especially within the following three months. The reliance on single measurements may not be of great help given that IBD activity changes, sometimes rapidly, over time. Recently, post hoc analyses of clinical trials indicate that repeated measurements of faecal calprotectin every second or third month can predict future flares in selected patient populations, such as Crohn's disease patients treated with anti-TNF therapy and ulcerative proctitis patients treated with 5-ASA. ${ }^{13,14}$ However, any attempt to identify an 
absolute cut-off will be limited by pronounced inter-assay differences ${ }^{15-17}$ and will probably be disease and phenotype specific. Therefore, we aimed to assess whether consecutive measurements of faecal calprotectin every third month can be used to monitor unselected patients with IBD in clinical remission. More specifically, we wanted to evaluate whether change in faecal calprotectin between consecutively collected samples was associated with increased risk of future flare.

\section{Materials and methods}

\section{Patients and study design}

This is a 24-month prospective study where patients aged 18 years or older, with a confirmed diagnosis of Crohn's disease or ulcerative colitis, were consecutively screened for participation while attending the outpatient Gastroenterology Clinic at Örebro University Hospital. Patients in clinical remission based on the physician's global assessment ${ }^{18}$ were eligible for inclusion irrespective of medication. Exclusion criteria were previous substantial surgical resections or any other systemic disease. Information on disease phenotype according to the Montreal classification ${ }^{19}$ was extracted from the medical notes. Patients were asked to fill in a questionnaire and to provide a faecal sample at baseline. A faecal sample and a filled-in questionnaire was subsequently obtained every third month until the first clinical relapse or the end of the 24-month follow-up period. The questionnaire included questions on patient-reported outcome measures (e.g. number of stools/day, abdominal pain, blood and mucus in stool), daily rating of quality of life, ${ }^{20}$ present IBD therapy, dietary habits, and use of antibiotics or NSAIDs . Patients were followed with scheduled appointments according to clinical routine and instructed to contact the outpatient clinic if gastrointestinal symptoms consistent with a relapse of IBD occurred between appointments during follow up. Relapse was defined as increasing symptoms 
necessitating intensified medical therapy or surgery. If a patient did not provide a faecal sample at any of the three-month periods, a written reminder was sent.

\section{Faecal calprotectin measurement}

Faecal samples were collected in screw-capped plastic containers, sent the same day by mail to the laboratory, and stored at $-70^{\circ} \mathrm{C}$. Faecal calprotectin was extracted and analysed with ELISA according to the manufacturer's protocol (EK-CAL, Bühlmann Lab. AG, Switzerland) after all patients had ended the follow up. Consequently, the results of the faecal calprotectin measurements did not influence any clinical decisions. Faecal calprotectin levels were expressed as micrograms of faecal calprotectin per gram of faeces, with the limit of detection (LOD) 10 $\mu \mathrm{g} / \mathrm{g}$

\section{Statistics}

Continuous variables with skewed distribution are presented as median and interquartile range (IQR). Differences between groups were compared using the Mann-Whitney U test, and frequencies were compared using the Chi-squared test. Variables that potentially affected sampling completeness were assessed using the logistic regression model.

The predictive value of faecal calprotectin was assessed in the extended Cox regression model that allows for non-proportional hazards by including an interaction term between faecal calprotectin and time. The hazard ratios (HR) with corresponding 95\% confidence interval (CI) were calculated. Missing faecal calprotectin values were imputed with the "last observation carried forward" technique. ${ }^{21}$ For faecal calprotectin levels below the LOD $10 \mu \mathrm{g} / \mathrm{g}, 10 / \sqrt{ } 2$ served as a substitute. ${ }^{22}$ To comply with the requirement of normal distribution for continuous dependent variables, analyses were carried on base 2 log-transformed faecal calprotectin values. 
We performed a sensitivity analysis by including different covariates that might confound the effect of the faecal calprotectin in the Cox regression model. Model 1 included baseline faecal calprotectin, age, and the interaction term between faecal calprotectin and time. Model 2 included time-varied faecal calprotectin, age, sex, and the interaction term between FC and time. Model 3 included time-varied FC, age, sex, and the interaction term between faecal calprotectin and time adjusted for medical treatments (oral corticosteroids, local corticosteroids, oral sulfasalazine, oral 5-aminosalicylic acid, local 5-aminosalicylic acid, immunomodulators, and anti-TNF therapy).

The analysis of linear mixed models, with allowance for dependence of faecal calprotectin values within the diagnosis and the study individual, was used to assess the influence of lifestyle factors, disease activity variables, and current treatments on faecal calprotectin levels. A twosided $p$ value of $<0.05$ was considered statistically significant for all analyses.

The Ethics Committee of Uppsala University approved the study (Drn 2007/291). All patients signed written informed consent.

\section{Results}

\section{Patients}

In total, 169 patients were screened; 17 patients declined to participate, and 22 patients had active disease (Figure 1). Of the remaining 130 patients, 26 did not provide a faecal sample and were excluded from the analyses. Thus, 104 patients, Crohn's disease $(n=49)$ and ulcerative colitis $(n=55)$, entered the analysis and provided 525 faecal samples during the follow up, 6 samples of which were discarded due to inadequate packaging. A complete set of faecal samples was obtained from 61 patients, whereas 43 patients did not provide a faecal sample on one or 
more occasions. Factors affecting sampling completeness were age at diagnosis $(\mathrm{p}=0.005)$ and age at enrolment $(\mathrm{p}=0.013)$, where patients younger than 40 years of age less often provided a complete sample set. A significant correlation between age at diagnosis and age at enrolment was observed $(\mathrm{R}=0.585, \mathrm{p}<0.0001)$, necessitating the adjustment of main analysis for only one of these variables.

Figure 1. Flow chart over the patient recruitment process, including information on number of patients providing complete set of samples and number of patients with incomplete set of samples.

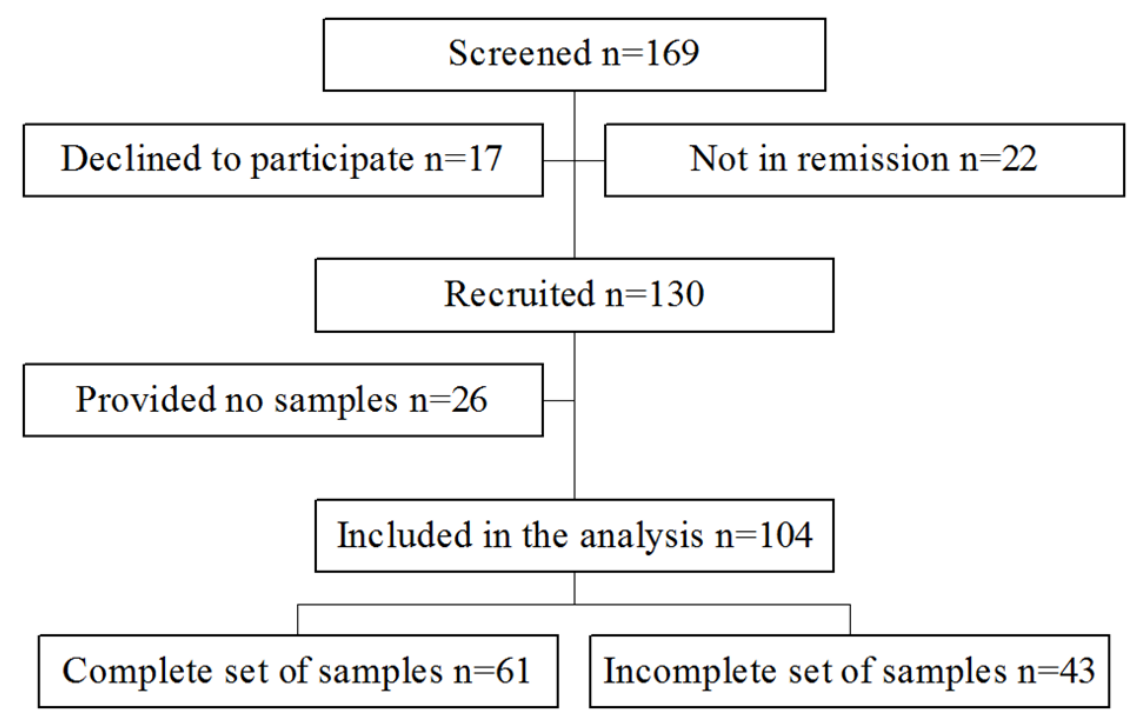

During follow up, 37 patients experienced a clinical relapse, and 67 remained in clinical remission. No differences were observed between the patients who relapsed and those who remained in clinical remission in terms of baseline demographics or clinical characteristics, but the proportion of patients treated with oral corticosteroids at baseline seemed to be higher in Crohn's disease and ulcerative colitis patients that relapsed during the study period, $\mathrm{p}=0.049$ and $\mathrm{p}=0.053$, respectively $($ Table 1$)$. 
Table 1. Data on demographics, clinical characteristics and treatment at baseline in study patients that relapsed or remained in clinical remission during the study.

\begin{tabular}{|c|c|c|}
\hline & Relapse & Remission \\
\hline \multicolumn{3}{|l|}{ Crohn's disease } \\
\hline $\mathrm{n}$ & 16 & 33 \\
\hline Age (years; median (IQR)) & $50(42-61)$ & $58(41-64)$ \\
\hline Males & $7(43.8 \%)$ & $17(51.5 \%)$ \\
\hline $\begin{array}{l}\text { Disease duration } \\
\text { (years; median (IQR)) }\end{array}$ & $18.5(9.75-22.5)$ & $25(11.5-38)$ \\
\hline Previous bowel resection & $7(43.8 \%)$ & $22(66.7 \%)$ \\
\hline $\begin{array}{l}\text { Baseline FC }(\mu \mathrm{g} / \mathrm{g} \text {; median } \\
(\mathrm{IQR}))\end{array}$ & $403(85-590)$ & $171(62-458)$ \\
\hline $\begin{array}{l}\text { Location } \\
\text { L1 (Ileal) }\end{array}$ & $4(25.0 \%)$ & $9(27.3 \%)$ \\
\hline L2 (Colonic) & $7(43.8 \%)$ & $8(24.2 \%)$ \\
\hline L3 (Ileocolonic) & $5(31.3 \%)$ & $16(48.5 \%)$ \\
\hline \multicolumn{3}{|l|}{ Behaviour } \\
\hline $\begin{array}{l}\text { B1 (Non-stricturing/non- } \\
\text { penetrating) }\end{array}$ & $8(50.0 \%)$ & $10(30.3 \%)$ \\
\hline B2 (Stricturing) & $4(25.0 \%)$ & $14(42.4 \%)$ \\
\hline B3 (Penetrating) & $4(25.0 \%)$ & $9(27.3 \%)$ \\
\hline $\mathrm{P}$ (Perianal disease) & $1(6.3 \%)$ & $7(21.2 \%)$ \\
\hline No treatment & $3(18.8 \%)$ & $11(33.3 \%)$ \\
\hline $\begin{array}{l}\text { Topical corticosteroids and/or 5- } \\
\text { ASA }\end{array}$ & $0(0 \%)$ & $1(3.0 \%)$ \\
\hline Oral 5-ASA or sulfasalazine & $5(31.3 \%)$ & $9(27.3 \%)$ \\
\hline Oral corticosteroids & $5(31.3 \%)$ & $3(9.1 \%)$ \\
\hline Immunomodulators & $8(50.0 \%)$ & $16(48.5 \%)$ \\
\hline Anti-TNF therapy & $1(6.3 \%)$ & $1(3.0 \%)$ \\
\hline \multicolumn{3}{|l|}{ Ulcerative colitis } \\
\hline $\mathrm{n}$ & 21 & 34 \\
\hline Age (years; median (IQR)) & $56(38-65)$ & $59(49-65)$ \\
\hline Males & $8(38.1 \%)$ & $18(52.9 \%)$ \\
\hline $\begin{array}{l}\text { Disease duration } \\
\text { (years; median (IQR)) }\end{array}$ & $11(4.5-16)$ & $20.5(10-29)$ \\
\hline $\begin{array}{l}\text { Baseline FC }(\mu \mathrm{g} / \mathrm{g} ; \text { median } \\
(\mathrm{IQR}))\end{array}$ & $92(29-551)$ & $100(33-277)$ \\
\hline E2 (Left-sided) & $9(42.9 \%)$ & $16(47.1 \%)$ \\
\hline E3 (Extensive) & $10(47.6 \%)$ & $14(41.2 \%)$ \\
\hline No treatment & $1(4.8 \%)$ & $5(14.7 \%)$ \\
\hline $\begin{array}{l}\text { Topical corticosteroids and/or 5- } \\
\text { ASA }\end{array}$ & $2(9.5 \%)$ & $2(5.9 \%)$ \\
\hline Oral 5-ASA or sulfasalazine & $10(47.6 \%)$ & $22(64.7 \%)$ \\
\hline Oral corticosteroids & $6(23.8 \%)$ & $2(5.9 \%)$ \\
\hline Immunomodulators & $7(33.3 \%)$ & $12(35.3 \%)$ \\
\hline Anti-TNF therapy & $0(0 \%)$ & $2(5.9 \%)$ \\
\hline
\end{tabular}




\section{Predictive value of baseline faecal calprotectin measurement}

The frequency of relapse was 37/104 (35.6\%) during the two-year study period in the entire study population regardless of faecal calprotectin. To determine if baseline faecal calprotectin influenced the risk of relapse, we analysed baseline faecal calprotectin measurements in an extended Cox regression model that allowed non-proportional hazards, (Model 1). Holding all other covariates at their means, the risk of relapse was increased by $47 \%$ (HR: $1.47 ; 95 \% \mathrm{CI}$ : 1.09-1.99, $\mathrm{p}=0.012$ ) per unit increase in log2-transformed baseline faecal calprotectin (Table 3, Model 1). In other words, a doubling of the baseline faecal calprotectin concentration resulted in a $47 \%$ increased risk of clinical relapse. Inclusion of age as predictor of relapse in the model did not change the results. A significant interaction between time until relapse and baseline faecal calprotectin was observed $(\mathrm{p}=0.017)$, which indicates that the proportional hazard assumption does not hold. In other words, the hazard ratio of the baseline faecal calprotectin changed across time.

To further explore the influence of baseline faecal calprotectin on time until relapse, patients were categorized into three groups based on the concentration of faecal calprotectin at baseline $(<250 \mu \mathrm{g} / \mathrm{g}, 250-500 \mu \mathrm{g} / \mathrm{g},>500 \mu \mathrm{g} / \mathrm{g})$. A low baseline faecal calprotectin was associated with a lower cumulative relapse frequency, both at 3 months $(\mathrm{p}=0.011)$ and 12 months $(\mathrm{p}=0.014$, Table 2). However, the association did not remain significant when the entire study period of 24 months was taken into account $(\mathrm{p}=0.140)$.

Table 2. Cumulative number of patients with clinical relapse during the 24-month follow up in relation to baseline concentration of faecal calprotectin. 


\begin{tabular}{cccc} 
& $0-3$ months & $0-12$ months & $0-24$ months \\
\hline \multirow{2}{*}{250} & $2 / 61(3.3 \%)$ & $9 / 61(14.8 \%)$ & $19 / 61(31.1 \%)$ \\
$250-500$ & $1 / 21(4.8 \%)$ & $5 / 21(23.8 \%)$ & $7 / 21(33.3 \%)$ \\
$>500$ & $5 / 22(22.7 \%)$ & $10 / 22(45.4 \%)$ & $11 / 22(50.0 \%)$ \\
Total & $8 / 104(7.7 \%)$ & $24 / 104(23.1 \%)$ & $37 / 104(35.6 \%)$ \\
\hline
\end{tabular}

FC; faecal calprotectin

Predictive value of consecutive faecal calprotectin measurements over time

Serial estimations of faecal calprotectin every third month indicated stable concentrations in the patients that remained in remission throughout the follow up (Figure 2). In patients with a clinical relapse, the concentration of faecal calprotectin at the time of relapse $(t=0)$ was significantly elevated, $513 \mu \mathrm{g} / \mathrm{g}$ (231-1173), compared to those in sustained remission, $162 \mu \mathrm{g} / \mathrm{g}$ (53-264), $\mathrm{p}<0.0001$. At time point -3 months, the concentration of faecal calprotectin was 305 $\mu \mathrm{g} / \mathrm{g}(72-827)$ in patients that subsequently relapsed compared to $197 \mu \mathrm{g} / \mathrm{g}(51-468)$ in patients that maintained remission $(\mathrm{p}=0.12)$. Individual data points of faecal calprotectin are shown in figure $3 \mathrm{~A}-\mathrm{B}$ for time points $-6,-3$, and 0 months.

Figure 2. Serial estimations of faecal calprotectin in patients with Crohn's disease or ulcerative colitis: time 0 refers to the end of the study period or time of relapse. Data are shown as boxes (median and IQR), separately for patients with relapse and for patients with sustained clinical remission during the study period. FC: faecal calprotectin 


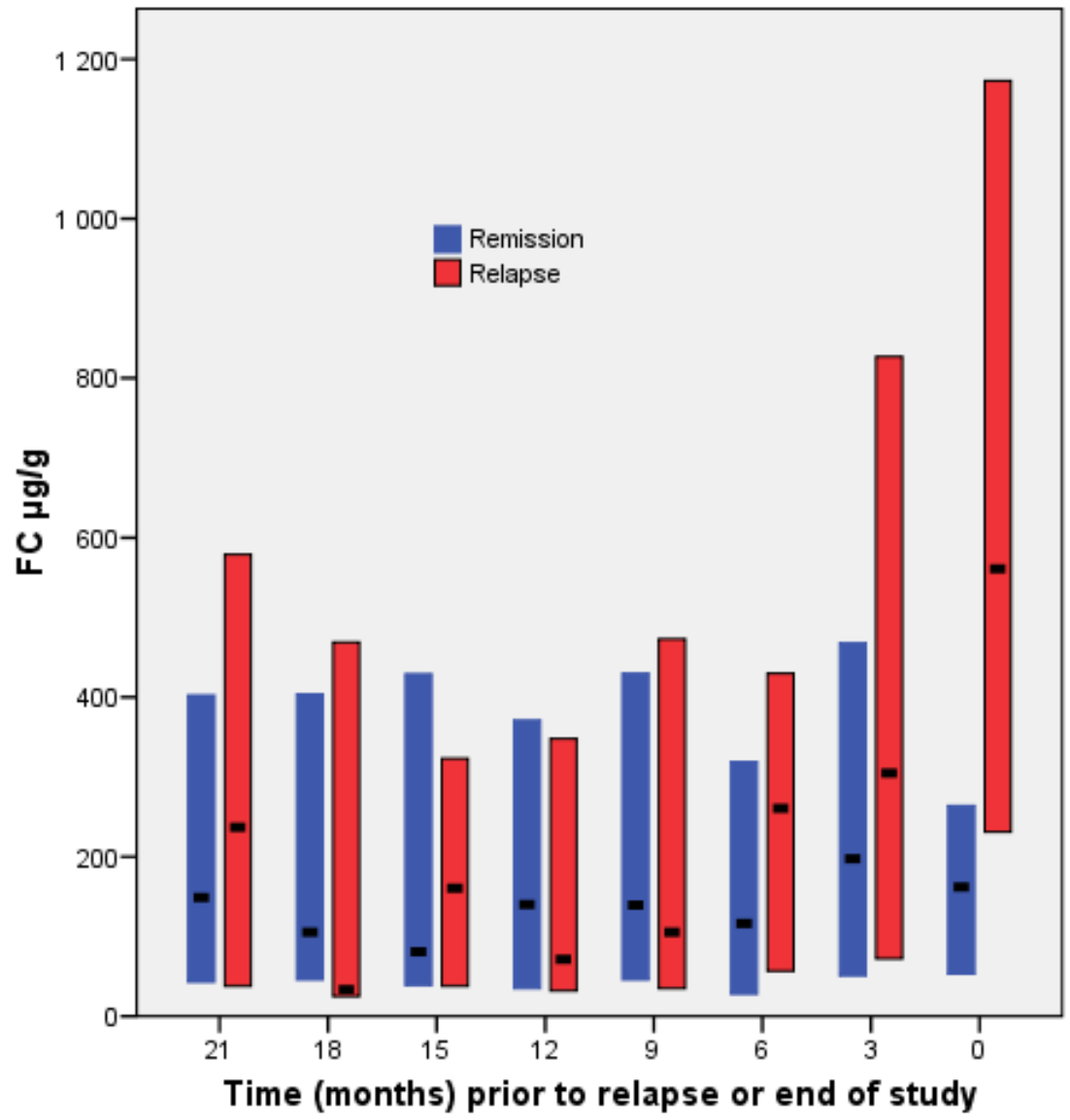

Figure 3. Individual data points for serial estimations of faecal calprotectin in patients with Crohn disease or ulcerative colitis. A) Patients that maintained remission: time 0 refers to the end of the study period. B) Patients that had a clinical relapse: time 0 refers to the time of relapse.

$3 \mathrm{~A}$ 


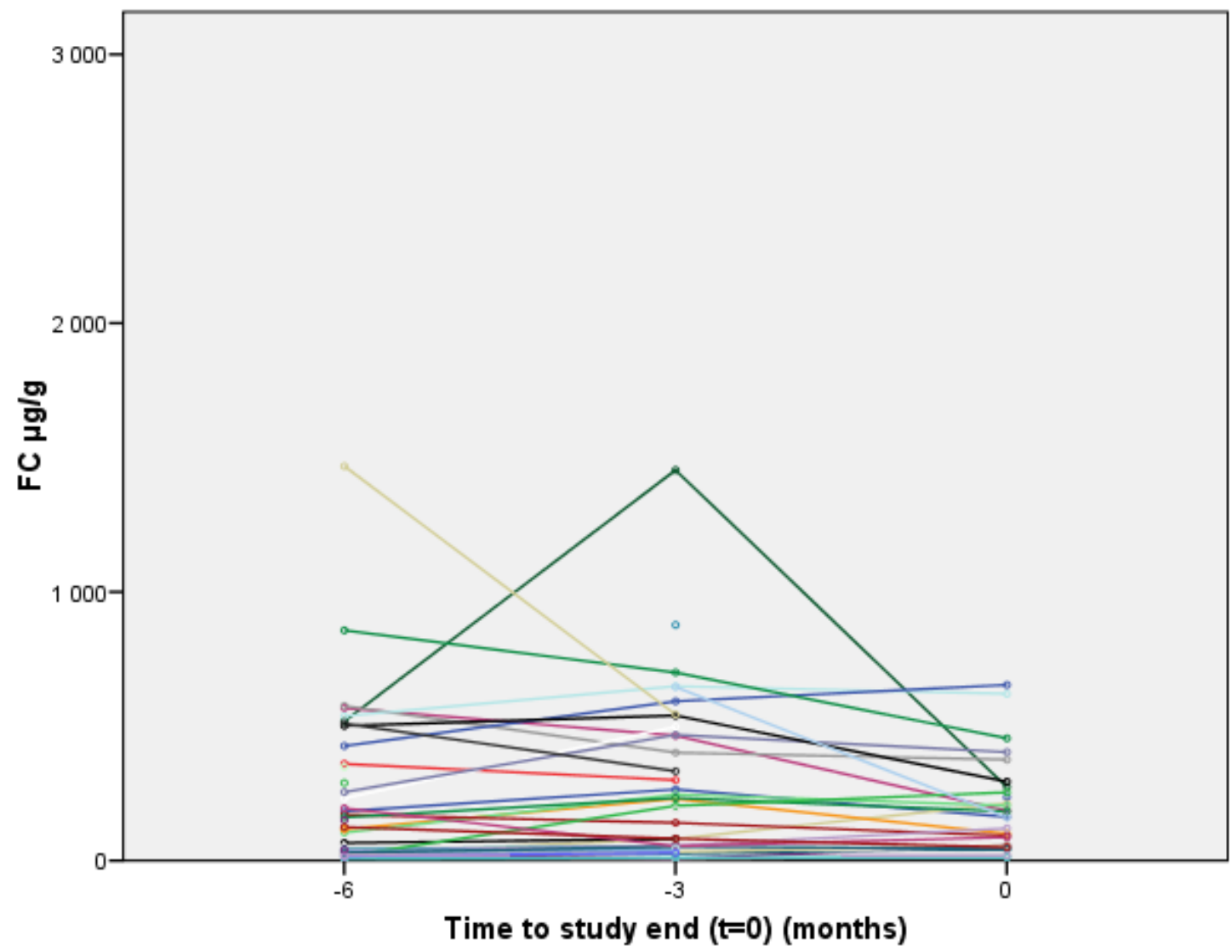




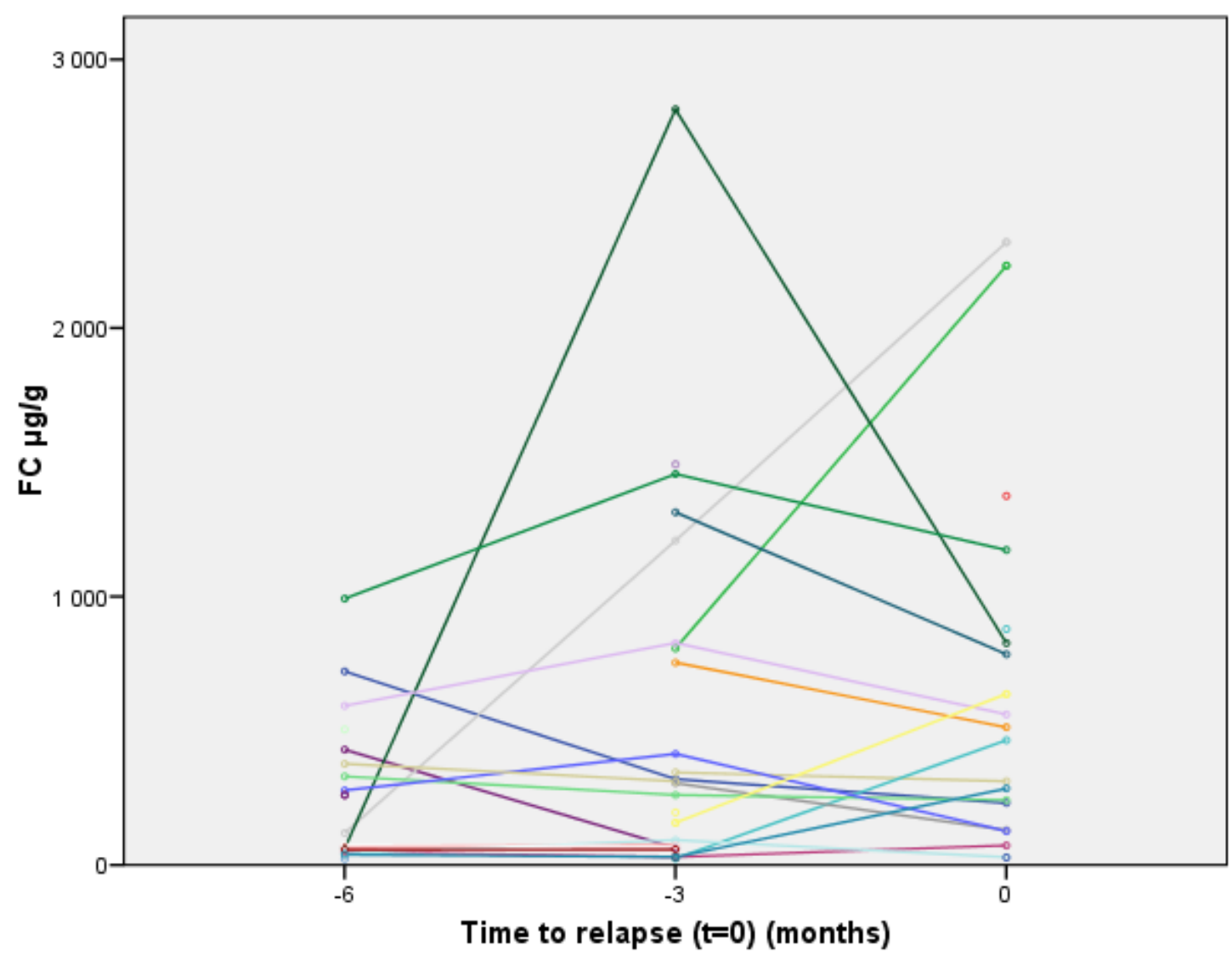

To investigate the effect of time-variant faecal calprotectin, we treated faecal calprotectin as a segmented time-variant variable in the extended Cox regression model (Model 2). A doubled risk of relapse was observed per a doubling of the faecal calprotectin concentration (HR: $2.01 ; 95 \%$ CI: $1.53-2.65 ; \mathrm{p}<0.001)$. There was an interaction between faecal calprotectin and time of follow up (HR: $0.80 ; 95 \%$ CI: $0.75-0.86 ; p<0.001$ ), which means that the predicted risk of relapse would be decreased by $20 \%$ when the time since the faecal calprotectin sample was obtained was increased by a unit, i.e. three months (Table 3, Model 2). In other words, the most recent faecal calprotectin has the strongest association with the relapse. The risk of relapse and the time interaction remained significant when the analysis was performed for Crohn's disease and 
ulcerative colitis patients separately, (HR: 2.37; 95\% CI: 1.46-3.87; p=0.001) and (HR: 1.57;

95\% CI: 1.11-2.23; $\mathrm{p}=0.012)$, respectively.

\section{Potential confounding lifestyle or treatment factors}

To explore whether faecal calprotectin levels were systematically confounded by any additional variables other than those included in Model 2 (IBD therapy, patient characteristics, patient reported outcomes, diet, and use of antibiotics or NSAIDs), we used analysis of mixed models design to allow for dependence of faecal calprotectin within a diagnosis and an individual. Male sex and poor general well-being were associated with higher faecal calprotectin levels, $(\mathrm{p}=0.03)$ and $(\mathrm{p}<0.001)$, respectively (Supplement Table 1).

Supplement Table 1. Associations between $\log 2$-transformed faecal calprotectin and lifestyle-, patient reported outcomes-, and treatment factors by linear mixt modelling.

\begin{tabular}{|c|c|c|c|c|}
\hline \multirow[b]{2}{*}{ Variables } & \multirow[b]{2}{*}{ Estimate } & \multicolumn{2}{|c|}{ 95\% Confidence Interval } & \multirow[b]{2}{*}{ Significance, $p$} \\
\hline & & Lower Bound & $\begin{array}{l}\text { Upper } \\
\text { Bound }\end{array}$ & \\
\hline Intercept & 6,90 & 5.21 & 8.58 & $<0.001$ \\
\hline Male sex & 0.76 & 0.08 & 1.44 & $\mathbf{0 . 0 3}$ \\
\hline Age & -0.02 & -0.05 & 0.01 & 0.14 \\
\hline $\begin{array}{l}\text { Antibiotic treatment within the last } \\
12 \text { months }\end{array}$ & 0.10 & -0.23 & 0.42 & 0.56 \\
\hline $\begin{array}{l}\text { Use of NSAID within the last } 12 \\
\text { months }\end{array}$ & 0.27 & -0.03 & 0.56 & 0.08 \\
\hline $\begin{array}{l}\text { Gastroenteritis within the last } 3 \\
\text { months }\end{array}$ & -0.03 & -0.41 & 0.35 & 0.89 \\
\hline Use of specific diet & 0.02 & -0.59 & 0.62 & 0.95 \\
\hline $\begin{array}{l}\text { Consumption of bacterial culture } \\
\text { within last week }\end{array}$ & 0.01 & -0.32 & 0.34 & 0.96 \\
\hline Blood in stools & 0.34 & -0.19 & 0.86 & 0.21 \\
\hline Mucous in stools & 0.35 & -0.04 & 0.74 & 0.08 \\
\hline $\begin{array}{l}\text { Daily rating of quality of life (IBD } \\
\text { today) }\end{array}$ & 0.53 & 0.26 & 0.80 & $<0.001$ \\
\hline Number of bowel movements & 0.03 & -0.13 & 0.19 & 0.72 \\
\hline Number of loose stools & 0.001 & -0.15 & 0.16 & 0.98 \\
\hline Oral steroids & -0.48 & -1.06 & 0.10 & 0.11 \\
\hline
\end{tabular}




\begin{tabular}{|l|l|l|l|l|}
\hline Topical steroids & 0.87 & -0.16 & 1.89 & 0.10 \\
\hline Oral 5-aminosalicylic acid & 0.52 & -0.09 & 1.13 & 0.09 \\
\hline Oral sulfasalazine & 0.21 & -0.52 & 0.94 & 0.57 \\
\hline Topical 5-aminosalicylic acid & 0.39 & -0.54 & 1.32 & 0.41 \\
\hline Immunomodulator & -0.15 & -0.78 & 0.47 & 0.63 \\
\hline Anti-TNF therapy & 0.68 & -1.23 & 2.59 & 0.48 \\
\hline
\end{tabular}

Despite the finding that IBD therapy did not confound the faecal calprotectin levels, we decided to validate this further by adding the treatment options (oral or topical 5-ASA, oral or topical corticosteroid treatment, immunomodulators or anti-TNF) as covariates to the extended Cox regression model (Model 3). The associations remained significant and very similar HRs were observed when the model was adjusted for treatments (Table 3, Model 3). The concentrations of faecal calprotectin according to the treatments are presented in Supplement Table 2.

Table 3. Data from extended Cox regression on predictors of clinical relapse analysed by Model 1, including baseline faecal calprotectin, age, and product of baseline faecal calprotectin $\mathrm{x}$ time; Model 2, including time variant faecal calprotectin, age, sex, and product of time-variant faecal calprotectin and time; and Model 3, including time-variant faecal calprotectin, age, sex, product of time-variant faecal calprotectin, and different treatment factors.

\section{Model 1}

\begin{tabular}{lcccc}
\hline & \multicolumn{4}{c}{$95 \%$ Confidence Interval } \\
Predictors & HR & Lower Bound & $\begin{array}{c}\text { Upper } \\
\text { Bound }\end{array}$ & P value \\
\hline Baseline FC & 1.47 & 1.09 & 1.99 & $\mathbf{0 . 0 1}$ \\
Age & 0.99 & 0.97 & 1.02 & 0.66 \\
$\begin{array}{l}\text { Baseline FC*Time (in 3 months } \\
\text { intervals) }\end{array}$ & 0.001 & 0.0 & 0.19 & $\mathbf{0 . 0 2}$ \\
\hline
\end{tabular}

Model 2

\begin{tabular}{lcccc}
\hline & & \multicolumn{2}{c}{$95 \%$ Confidence Interval } & \\
\cline { 3 - 4 } Predictors & HR & Lower Bound & $\begin{array}{c}\text { Upper } \\
\text { Bound }\end{array}$ P value \\
\cline { 1 - 3 } Time-variant FC & 2.01 & 1.53 & 2.65 & $<\mathbf{0 . 0 0 1}$ \\
Age & 1.01 & 0.98 & 1.04 & 0.67 \\
Male sex & 1.40 & 0.56 & 3.47 & 0.47
\end{tabular}


Calprotectin*Time (in 3 months intervals)

Model 3

\begin{tabular}{lcccc}
\hline & & \multicolumn{2}{c}{$95 \%$ Confidence Interval } & \\
\cline { 3 - 4 } Predictors & HR & Lower Bound & Upper & Bound \\
\hline Time-variant FC & 2.17 & 1.57 & 2.99 & $<\mathbf{0 . 0 0 1}$ \\
Age & 1.01 & 0.97 & 1.01 & 0.74 \\
Male sex & 1.41 & 0.52 & 3.78 & 0.50 \\
Oral steroids & 1.16 & 0.40 & 3.33 & 0.78 \\
Topical steroids & 2.61 & 0.26 & 26.01 & 0.41 \\
Oral 5-aminosalicylic acid & 1.48 & 0.60 & 3.69 & 0.40 \\
Oral sulfasalazine & 1.54 & 0.49 & 4.84 & 0.46 \\
Topical 5-aminosalicylic acid & 0.82 & 0.08 & 8.11 & 0.87 \\
Immunomodulator & 1.70 & 0.70 & 4.14 & 0.24 \\
Anti-TNF therapy & 0.98 & 0.08 & 12.50 & 0.99 \\
Calprotectin* Time (in 3 months & & & & \\
intervals) & 0.79 & 0.73 & 0.85 & $<\mathbf{0 . 0 0 1}$ \\
\hline
\end{tabular}

HR, Hazard ratio; FC, faecal calprotectin.

Supplement Table 2. Faecal calprotectin, median and interquartile range, in relation to ongoing medical treatment during the study period.

\begin{tabular}{lcc}
\hline & \multicolumn{2}{c}{ FC $\mu \mathrm{g} / \mathrm{g}$ median (IQR) } \\
& Treated & Not treated \\
\hline Oral steroids & $402(204-588)$ & $119(39-402)$ \\
Local steroids & $465(312-754)$ & $126(40-404)$ \\
Oral 5-aminosalicylic acid & $137(30-407)$ & $130(44-414)$ \\
Oral sulfasalazine & $171(56-376)$ & $119(37-425)$ \\
Local 5-aminosalicylic acid & $178(49-283)$ & $130(40-414)$ \\
Immunomodulator & $81(28-410)$ & $171(52-413)$ \\
Anti-TNF therapy & $263(114-528)$ & $128(40-411)$ \\
\hline
\end{tabular}

FC, faecal calprotectin

\section{Discussion}

In this prospective study, we explored whether the dynamics of faecal calprotectin were associated with the risk of a future flare in an unselected cohort of patients with IBD in clinical remission. We observed a $101 \%$ increased risk of clinical relapse within the following three- 
month period per unit increase in $\log 2$-transformed consecutive faecal calprotectin measurements. An interaction between faecal calprotectin and time was also detected, corresponding to a $20 \%$ decrease in predicted risk of clinical relapse per three-month period since the sample was obtained. In clinical practice this would mean that a twofold increase of faecal calprotectin between two consecutive measurements with a three-month interval translates into a doubled risk of relapse within the following three months. The association between change in faecal calprotectin and risk of disease relapse is not constant over time. Should the patient not develop a clinical relapse within this period, the increased risk during the subsequent threemonth period is $20 \%$ smaller. In other words, the most recent faecal calprotectin has the strongest association with relapse.

Numerous studies have revealed that faecal calprotectin correlates with the inflammatory activity in IBD, especially in patients with colorectal inflammation. ${ }^{23}$ Tibble et al. studied IBD patients in clinical remission and observed a thirteenfold increase in risk of clinical relapse within the 12month follow-up period in patients with faecal calprotectin> $50 \mathrm{mg} / \mathrm{L}$, although 59 of the 80 patients who experienced a relapse did so within the first three months. ${ }^{3}$ Since then, many studies have confirmed this pivotal observation, but the proposed cut-off for identifying patients who are at increased risk of relapse differs between the studies..$^{9,24,25}$ One explanation for these cut-off differences are the pronounced inter-assay differences. ${ }^{15-17}$ Another explanation is that cut-offs are disease and phenotype specific, since differences in the concentrations of FC have been reported between subgroups of patients with IBD, i.e. patients with ileal and colonic Crohn's disease. We did not try to find a specific cut-off value of faecal calprotectin, as this has been known to lead to results that are highly specific to the study sample and, therefore, unlikely to be generalized. Furthermore, it would have led to estimates that are less precise because of the decrease in the number of patients with higher levels. 
Faecal calprotectin is a highly dynamic biomarker of intestinal inflammation and is known to vary during the follow-up time. The rationale of our study was based on the assumption that faecal calprotectin may increase while the disease remains without clinical manifestations for some time. We collected repeated measures of faecal calprotectin every three months and analysed them with appropriate technique, such as time-dependent covariate in the extended Cox regression model. This model allows values of a biological variable to be updated every fixedtime interval. Because the value of faecal calprotectin changed every three months, the value introduced at any time in the model was the last known value before that time.

Patients seen in everyday clinical practice tend to be quite heterogeneous. Remarkably, the use of serial measurements of faecal calprotectin for monitoring disease activity has only been explored in highly selected groups so far, such as anti-TNF treated patients and 5-ASA treated ulcerative proctitis patients within a clinical-trial setting. ${ }^{13,14}$ De Vos et al. reported that sustained deep remission could be predicted by sustained low faecal calprotectin, when measured every four weeks, in patients with ulcerative colitis in clinical remission under infliximab maintenance therapy. On the contrary, in Crohn's disease patients responding to an IFX-induction regimen, faecal calprotectin measurement at week 14 could not predict clinical relapse at one year. ${ }^{26}$ By analysing consecutively recruited patients with IBD at an outpatient clinic, we extended previous reports on highly selected groups of patients to the general IBD population. Our data show that a twofold increase of faecal calprotectin between two consecutive samples with a three-month interval is associated with a doubled risk of relapse. The corresponding absolute risk depends on the baseline risk associated with faecal calprotectin in the first sample. For example, a patient who experiences an increase in faecal calprotectin from $20 \mu \mathrm{g} / \mathrm{g}$ to $40 \mu \mathrm{g} / \mathrm{g}$ still has a low absolute risk of developing relapse. 
As with many other biomarkers, the distribution of faecal calprotectin is right-skewed. To allow analyses of normalised continuous data and to take the dependence of faecal calprotectin within each individual into account, the concentrations of faecal calprotectin were log2transformed and then analysed in an extended Cox regression model as a continuous trait instead of as a categorical variable.

The variability in the concentrations of faecal calprotectin in patients with IBD depends on disease activity, ${ }^{27-29}$ stool consistency, and time between bowel movements. Lasson et al. found that the longer the time between bowel movements and the looser the stool consistency, the higher the concentrations of faecal calprotectin. ${ }^{30}$ Associations between faecal calprotectin and age, obesity, physical inactivity, fibre intake, as well as vegetable consumption have also been reported in healthy individuals. ${ }^{31}$ Therefore, we explored the influence of patient characteristics, patient reported outcome measures, use of antibiotics or NSAIDs, as well as dietary effects on faecal calprotectin in our dataset. NSAIDs have previously been associated with increased FC levels, ${ }^{32-34}$ although the association did not really reach significance in our cohort. Increased concentrations of faecal calprotectin were observed in patients with poor daily rating of quality of life. It can be assumed that this may be caused by symptoms due to active bowel inflammation. However, independent associations with other dimensions of patient reported outcomes, like the number of bowel movements or blood in stool, could not be statistically confirmed in the entire IBD population, probably due to small sample size. In addition, an association between increased faecal calprotectin and male sex was also observed. This has been reported previously, ${ }^{35}$ but the pathophysiologic explanation for the observed association between sex and concentration of faecal calprotectin can be only speculated on.

The major strength of this study was the prospective measurement of faecal calprotectin over a two-year period in consecutively recruited patients at an outpatient clinic. The fact that the 
measurements of faecal calprotectin were performed after completion of the study period and that the clinical decisions were not influenced by the observed results reduced the risk of differential bias. The observation that the results remained significant when adjusting for possible confounders, such as IBD therapy, patient characteristics, diet, and use of antibiotics or NSAIDs, further strengthen this study.

The fact that neither clinical remission at baseline nor clinical relapse during follow up were confirmed by endoscopy is a limitation of the study. However, repeated endoscopies are not accepted by patients and are associated with costs and risks. Similarly, co-monitoring of CRP was not regarded as feasible, since this would require admittance to health care every third month. Some patients were on corticosteroids at baseline, which might have influenced the relapse rate during the study period. The results might also be limited by the fact that $41 \%$ of the patients did not provide a faecal sample on one or several occasions. This problem was most pronounced among younger patients. However, none of the patients got feedback on their faecal calprotectin levels since faecal calprotectin was measured after all of the patients had completed their follow up. Another possible weakness of the study is that information on duration of clinical remission at baseline was not included in the analyses, since it is negatively associated with time to clinical relapse. ${ }^{36}$ Our patient group is heterogeneous, comprising both Crohn's disease and ulcerative colitis patients, regardless of clinical characteristics, such as location, behaviour, and disease extent. Despite that, the predictive value of faecal calprotectin remained statistically significant even when patients with Crohn's disease and ulcerative colitis were analysed separately.

In conclusion, our data suggest that longitudinal monitoring of faecal calprotectin is informative in evaluating risk of relapse in IBD. By consecutive measurement of faecal calprotectin every third month, we quantified the relative risk of relapse associated with faecal calprotectin change 
and observed attenuation of the risk across time. Future studies should evaluate whether early medical intervention is useful for the prevention of subsequent relapse in asymptomatic IBD patients with elevated faecal calprotectin levels and examine the cost-effectiveness of this monitoring regimen.

\section{Financial disclosures}

JH: speaker's honoraria from Abbvie, Janssen, MSD, Renapharma Vifor, Takeda; consultancy: Abbvie, Hospira, Janssen, Medevir, MSD, Pfizer, Takeda; shareholder: AstraZeneca

CT: speaker's honoraria from Dr. Falk Pharma, Tillotts Pharma, Ferring, MSD and AstraZeneca.

\section{Authorship statement}

YZ, YC, KA, MC, CT and JH contributed equally to the design of the study. YZ, KA and JH collected the data. KA analyzed the stool samples. YZ and $\mathrm{YC}$ analyzed the data. $\mathrm{YZ}$ wrote the article and all the other authors contributed with critical revision of the manuscript for important intellectual content and interpretation of the data. All authors read and approved the final version of the manuscript.

Funding: This work was supported by Örebro University Hospital Research Foundation (grant number OLL-333321); Swedish Foundation For Strategic Research (grant number RB13-0160); Uppsala-Örebro Regional Research Foundation (RFR-314671); Örebro County Research Foundation (grants number OLL-290301, OLL-172601, OLL-93671, OLL-122871); and Swedish Research Council (grant number 521-2011-2764).

\section{Acknowledgements}

We acknowledge Johan Bohr, Anna Wickbom, Nils Nyhlin, Yeshi Yimam for inclusion of study patients; Ahmed Salim, Carina Emilsson, Gun-Maj Lignell and Åsa Ekbom for the assistance with data collection; and Mats Stridsberg for supervising measurements of FC. 


\section{References}

1. Peyrin-Biroulet L, Ferrante M, Magro F, Campbell S, Franchimont D, Fidder H, Strid H, Ardizzone S, Veereman-Wauters G, Chevaux JB, Allez M, Danese S, Sturm A. Results from the 2nd Scientific Workshop of the ECCO. I: Impact of mucosal healing on the course of inflammatory bowel disease. J Crohns Colitis 2011;5(5):477-83.

2. Baert F, Moortgat L, Van Assche G, Caenepeel P, Vergauwe P, De Vos M, Stokkers P, Hommes D, Rutgeerts P, Vermeire S, D'Haens G. Mucosal healing predicts sustained clinical remission in patients with early-stage Crohn's disease. Gastroenterology 2010;138(2):463-8; quiz e10-1.

3. Tibble JA, Sigthorsson G, Bridger S, Fagerhol MK, Bjarnason I. Surrogate markers of intestinal inflammation are predictive of relapse in patients with inflammatory bowel disease. Gastroenterology 2000;119(1):15-22.

4. Meuwis MA, Vernier-Massouille G, Grimaud JC, Bouhnik Y, Laharie D, Piver E, Seidel L, Colombel JF, Louis E. Serum calprotectin as a biomarker for Crohn's disease. J Crohns Colitis 2013;7(12):e678-83.

5. Desai D, Faubion WA, Sandborn WJ. Review article: biological activity markers in inflammatory bowel disease. Aliment Pharmacol Ther 2007;25(3):247-55.

6. Gisbert JP, Marin AC, Chaparro M. Systematic review: factors associated with relapse of inflammatory bowel disease after discontinuation of anti-TNF therapy. Aliment Pharmacol Ther 2015;42(4):391-405. 
7. Tibble J, Teahon K, Thjodleifsson B, Roseth A, Sigthorsson G, Bridger S, Foster R, Sherwood R, Fagerhol M, Bjarnason I. A simple method for assessing intestinal inflammation in Crohn's disease. Gut 2000;47(4):506-13.

8. Canani RB, Terrin G, Rapacciuolo L, Miele E, Siani MC, Puzone C, Cosenza L, Staiano A, Troncone R. Faecal calprotectin as reliable non-invasive marker to assess the severity of mucosal inflammation in children with inflammatory bowel disease. Dig Liver Dis 2008;40(7):547-53.

9. D'Haens G, Ferrante M, Vermeire S, Baert F, Noman M, Moortgat L, Geens P, Iwens D, Aerden I, Van Assche G, Van Olmen G, Rutgeerts P. Fecal calprotectin is a surrogate marker for endoscopic lesions in inflammatory bowel disease. Inflamm Bowel Dis 2012;18(12):2218-24.

10. Kopylov U, Rosenfeld G, Bressler B, Seidman E. Clinical utility of fecal biomarkers for the diagnosis and management of inflammatory bowel disease. Inflamm Bowel Dis 2014;20(4):742-56.

11. D'Inca R, Dal Pont E, Di Leo V, Benazzato L, Martinato M, Lamboglia F, Oliva L, Sturniolo GC. Can calprotectin predict relapse risk in inflammatory bowel disease? Am J Gastroenterol 2008;103(8):2007-14.

12. Yamamoto T, Shiraki M, Bamba T, Umegae S, Matsumoto K. Fecal calprotectin and lactoferrin as predictors of relapse in patients with quiescent ulcerative colitis during maintenance therapy. Int J Colorectal Dis 2014;29(4):485-91.

13. De Vos M, Louis EJ, Jahnsen J, Vandervoort JG, Noman M, Dewit O, D'Haens G R, Franchimont D, Baert FJ, Torp RA, Henriksen M, Potvin PM, Van Hootegem PP, Hindryckx PM, Moreels TG, Collard A, Karlsen LN, Kittang E, Lambrecht G, Grimstad T, Koch J, Lygren I, Coche JC, Mana F, Van Gossum A, Belaiche J, Cool MR, Fontaine 
F, Maisin JM, Muls V, Neuville B, Staessen DA, Van Assche GA, de Lange T, Solberg IC, Vander Cruyssen BJ, Vermeire SA. Consecutive fecal calprotectin measurements to predict relapse in patients with ulcerative colitis receiving infliximab maintenance therapy. Inflamm Bowel Dis 2013;19(10):2111-7.

14. Yamamoto T, Shimoyama T, Matsumoto K. Consecutive monitoring of faecal calprotectin during mesalazine suppository therapy for active rectal inflammation in ulcerative colitis. Aliment Pharmacol Ther 2015;42(5):549-58.

15. Sun S, Cavey T, Peltier L, Bendavid C, Bouguen G. Letter: wide variation in faecal calprotectin values according to the assay. Aliment Pharmacol Ther 2016;43(1):177-8.

16. Kristensen V, Klepp P, Cvancarova M, Roseth A, Skar V, Moum B. Prediction of endoscopic disease activity in ulcerative colitis by two different assays for fecal calprotectin. J Crohns Colitis 2015;9(2):164-9.

17. Amcoff K, Lampinen M, Stridsberg M, Halfvarson J, Carlsson M. Assay specific differences in consecutively measured f-calprotectin in patients with IBD followed over time. United European Gastroenterology Journal 2014;2(1 suppl):A370.

18. Hanauer S, Schwartz J, Robinson M, Roufail W, Arora S, Cello J, Safdi M. Mesalamine capsules for treatment of active ulcerative colitis: results of a controlled trial. Pentasa Study Group. Am J Gastroenterol 1993;88(8):1188-97.

19. Satsangi J, Silverberg MS, Vermeire S, Colombel JF. The Montreal classification of inflammatory bowel disease: controversies, consensus, and implications. Gut 2006;55(6):749-53.

20. Hanauer SB, Robinson M, Pruitt R, Lazenby AJ, Persson T, Nilsson LG, Walton-Bowen K, Haskell LP, Levine JG. Budesonide enema for the treatment of active, distal ulcerative 
colitis and proctitis: a dose-ranging study. U.S. Budesonide enema study group. Gastroenterology 1998;115(3):525-32.

21. Woolley SB, Cardoni AA, Goethe JW. Last-observation-carried-forward imputation method in clinical efficacy trials: review of 352 antidepressant studies. Pharmacotherapy 2009;29(12):1408-16.

22. Hornung RW, Reed LD. Estimation of Average Concentration in the Presence of Nondetectable Values. Applied Occupational and Environmental Hygiene 1990;5(1):4651.

23. Sipponen T, Karkkainen P, Savilahti E, Kolho KL, Nuutinen H, Turunen U, Farkkila M. Correlation of faecal calprotectin and lactoferrin with an endoscopic score for Crohn's disease and histological findings. Aliment Pharmacol Ther 2008;28(10):1221-9.

24. Naismith GD, Smith LA, Barry SJ, Munro JI, Laird S, Rankin K, Morris AJ, Winter JW, Gaya DR. A prospective single-centre evaluation of the intra-individual variability of faecal calprotectin in quiescent Crohn's disease. Aliment Pharmacol Ther 2013;37(6):613-21.

25. Schoepfer AM, Beglinger C, Straumann A, Trummler M, Vavricka SR, Bruegger LE, Seibold F. Fecal calprotectin correlates more closely with the Simple Endoscopic Score for Crohn's disease (SES-CD) than CRP, blood leukocytes, and the CDAI. Am J Gastroenterol 2010;105(1):162-9.

26. Laharie D, Mesli S, El Hajbi F, Chabrun E, Chanteloup E, Capdepont M, Razaire S, de Ledinghen V, Zerbib F. Prediction of Crohn's disease relapse with faecal calprotectin in infliximab responders: a prospective study. Aliment Pharmacol Ther 2011;34(4):462-9. 
27. Roseth AG, Aadland E, Jahnsen J, Raknerud N. Assessment of disease activity in ulcerative colitis by faecal calprotectin, a novel granulocyte marker protein. Digestion 1997;58(2):176-80.

28. von Roon AC, Karamountzos L, Purkayastha S, Reese GE, Darzi AW, Teare JP, Paraskeva P, Tekkis PP. Diagnostic precision of fecal calprotectin for inflammatory bowel disease and colorectal malignancy. Am J Gastroenterol 2007;102(4):803-13.

29. Sipponen T, Savilahti E, Kolho KL, Nuutinen H, Turunen U, Farkkila M. Crohn's disease activity assessed by fecal calprotectin and lactoferrin: correlation with Crohn's disease activity index and endoscopic findings. Inflamm Bowel Dis 2008;14(1):40-6.

30. Lasson A, Stotzer PO, Ohman L, Isaksson S, Sapnara M, Strid H. The intra-individual variability of faecal calprotectin: a prospective study in patients with active ulcerative colitis. J Crohns Colitis 2015;9(1):26-32.

31. Poullis A, Foster R, Shetty A, Fagerhol MK, Mendall MA. Bowel inflammation as measured by fecal calprotectin: a link between lifestyle factors and colorectal cancer risk. Cancer Epidemiol Biomarkers Prev 2004;13(2):279-84.

32. Rendek Z, Falk M, Grodzinsky E, Wahlin K, Kechagias S, Svernlov R, Hjortswang H. Effect of oral diclofenac intake on faecal calprotectin. Scand J Gastroenterol 2016;51(1):28-32.

33. Tibble JA, Sigthorsson G, Foster R, Scott D, Fagerhol MK, Roseth A, Bjarnason I. High prevalence of NSAID enteropathy as shown by a simple faecal test. Gut 1999;45(3):3626.

34. Meling TR, Aabakken L, Roseth A, Osnes M. Faecal calprotectin shedding after shortterm treatment with non-steroidal anti-inflammatory drugs. Scand J Gastroenterol 1996;31(4):339-44. 
35. Amati L, Passeri ME, Selicato F, Mastronardi ML, Penna A, Jirillo E, Covelli V. New insights into the biological and clinical significance of fecal calprotectin in inflammatory bowel disease. Immunopharmacol Immunotoxicol 2006;28(4):665-81.

36. Riley SA, Mani V, Goodman MJ, Lucas S. Why do patients with ulcerative colitis relapse? Gut 1990;31(2):179-83. 